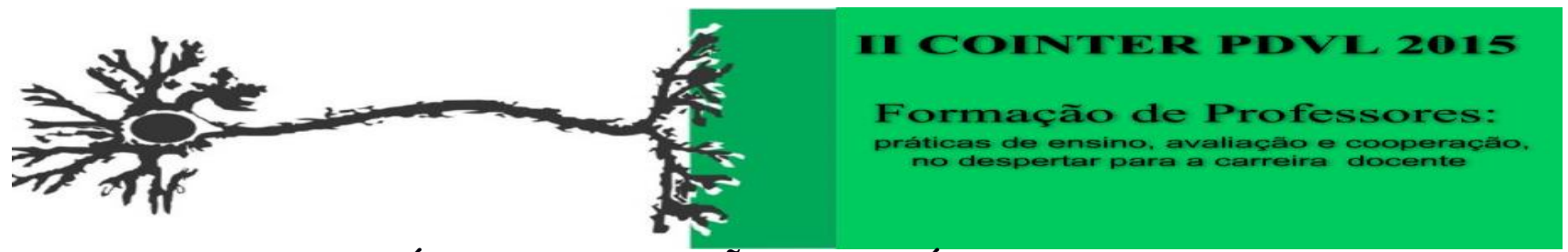

\title{
A ETNOMATEMÁTICA COMO AÇÃO PEDAGÓGICA NA APRENDIZAGEM DE FRAÇÃO E NÚMEROS DECIMAIS: “OS PREÇOS ESTÃO NA HORA DA MORTE”
}

\author{
Apresentação: Comunicação Oral \\ Hosana Silva de Santana ${ }^{1}$; Jakeline Carneiro de Oliveira ${ }^{2}$; Mirtes Ribeiro de Lira ${ }^{3}$
}

\begin{abstract}
Resumo
Este estudo teve como objetivo analisar o desempenho dos alunos da EJA sobre o conhecimento de frações e decimais a partir de uma ação intervenção. Para isso adotamos como aporte teórico a Etnomatemática como alternativa de ação pedagógica a qual procura entender a realidade de forma natural e chegar à ação pedagógica de forma espontânea por meio de um enfoque cognitivo levando em conta, especialmente, a cultura (PCNs, 1997). Participaram deste estudo 15 estudantes da turma do módulo $\mathrm{V}$ da Educação de Jovens e Adultos (EJA) de uma escola localizada no município de Jaboatão dos Guararapes-PE. A pesquisa foi realizada em três momentos: (1) aplicação do pré-teste no primeiro encontro; (2) no segundo encontro realização de uma intervenção didática sobre frações e números racionais e (3) aplicação do pós-teste. A ação pedagógica, na perspectiva etnomatemática foi gerada a partir da frase "OS PREÇOS ESTÃO NA HORA DA MORTE", na qual foi escrita no quadro e solicitada à opinião dos estudantes, se eles concordavam com esta afirmativa e em seguida foi realizado alguns questionamentos, tais como: O que estariam causando a alta dos preços? Como eles sabiam que os alimentos, produtos estavam com preços elevados? Onde os preços estavam mais altos nos produtos ou nos alimentos? A abordagem Etnomatemática nesse estudo nos permitiu estabelecer conexões matemáticas em sala de aula acompanhadas de maior significado para os alunos no ensino de frações e números decimais. Nesse sentido, entendemos que utilizar a etnomatemática como ação pedagógica nas aulas de EJA facilita muito a compreensão e a internalização dos conceitos, significados e representações dos números fracionários e decimais.
\end{abstract}

Palavras-Chave: Etnomatemática, ação pedagógica, Educação de Jovens e Adultos.

\section{Introdução}

A Matemática faz parte de nossa vida e a utilizamos nas mais variadas situações do nosso cotidiano. Mas, na grande maioria das vezes, os conteúdos matemáticos são trabalhados em sala de aula sem uma contextualização tornando a aprendizagem mecânica, sem sentido, no qual o educando não sabe por em prática o que aprendeu, pois na prática não há relação com a teoria.

Os alunos da Educação de Jovens e Adultos (EJA) enfrentam dificuldades em relacionar a Matemática com sua vivencia do cotidiano. Esta modalidade de ensino, amparada por lei é voltada para pessoas que não tiveram acesso, por algum motivo, ao ensino regular na idade apropriada, fazendo parte do sistema de ensino da rede pública no Brasil. Uma das grandes dificuldades

\footnotetext{
${ }^{1}$ Licenciatura em Matemática, Universidade de Pernambuco / Mata Norte, hosana26jeiel@outlook.com

${ }^{2}$ Licenciatura em Matemática, Universidade de Pernambuco/ Mata Norte, jake_oliveira22@hotmail.com

${ }^{3}$ Doutora em Educação, Universidade de Pernambuco campus Mata Norte, mirtes.lira@upe.br
} 
apontadas pela maioria dos professores deste nível de ensino é a aprendizagem do conteúdo de frações e números decimais.

Diante dessa problemática, a presente pesquisa tem como objetivo principal o analisar desempenho dos alunos da EJA sobre o conhecimento de frações e decimais a partir de uma ação intervenção. Para isso adotamos como aporte teórico a Etnomatemática como alternativa de ação pedagógica a qual procura entender a realidade de forma natural e chegar à ação pedagógica de forma espontânea por meio de um enfoque cognitivo levando em conta, especialmente, a cultura (PCNs, 1997).

\section{Fundamentação Teórica}

Nos dias atuais, com a evolução constante do ensino da Matemática, defende-se à ideia e a necessidade de ensinar de forma contextualizada, porém, muitos professores considera que contextualizar é apenas encontrar aplicações práticas para a Matemática no dia a dia do aluno. Fernandes (2006) vai além desta concepção, ele afirma que contextualizar é o ato de colocar no contexto, ou seja, colocar alguém a par de alguma coisa; uma ação premeditada para situar um indivíduo em lugar no tempo e no espaço desejado. Ele ressalta ainda, que a contextualização pode também ser entendida como uma espécie de argumentação ou uma forma de encadear ideias. A contextualização do conhecimento matemático em conteúdos de outras disciplinas é outra forma de mostrar a contribuição da Matemática na leitura dos diversos fenômenos naturais e sociais em que outras ciências se apresentam. Por isso, concordamos com Moraes (2010), ao afirmar que o objetivo de se trabalhar com a contextualização é dar condições para uma aprendizagem motivadora, que proporcione ao aluno fazer uma relação do conhecimento do seu cotidiano com a própria Matemática.

A contextualização no ensino da Matemática, não é trabalhar o conteúdo envolvendo apenas o cotidiano do estudante, e sim o envolvendo com contextos que tenham significado e possa mobilizá-lo para que se sintam motivados e percebam a importância da Matemática como mecanismo de transformação da realidade, e que também possa exercer a cidadania e sejam capazes de desenvolver uma atitude crítica diante dos problemas que envolvem o meio social em que vivem.

Diante disto, partimos do pressuposto que os conhecimentos matemáticos existentes em todas as culturas devem ser considerados como uma produção cultural e por isso são necessárias as diferentes abordagens apresentadas pela matemática nas diversas culturas, tais como: a Matemática da Educação de Jovens e Adultos (EJA), a Matemática dos assentamentos sem terra, a Matemática dos povos africanos entre outras. 
É observando as diferentes culturas que D’Ambrósio (1999) destaca que o contexto e os mitos abstraídos da realidade natural, aquilo que chamamos de cultura, são essenciais no desenvolvimento diferenciado desses diversos sistemas de códigos, símbolos e rituais. As representações incorporam-se à realidade como artefatos da mesma maneira que os mitos e símbolos, sem necessidade de recursos à codificação, também se incorporam à realidade, porém como mentefatos, ou seja, a religião, valores, filosofias, ideologias e ciências, como manifestações do saber, que se incorporam a realidade.

D’Ambrósio (1991) ratifica que cada grupo tem a sua própria Etnomatemática, mesmo a Matemática formal acadêmica é constituída por diferentes Etnomatemáticas, referindo-se às especificidades dos trabalhos desenvolvidos por algebristas e analistas e, inclusive, suas dificuldades de intercambiar seus conhecimentos, nesse sentido, o referido autor traz o significado da palavra etnomatemática como, "uma liberdade etimológica que permite usar as raízes etno para significar ambientes naturais e culturais, matema para significar explicar, conhecer, aprender, e tica para significar as maneiras e os modos" (p.35). Além de possuir caráter antropológico a Etnomatemática possui também um foco político, de forma ética, numa forma mais direcionada da recuperação da dignidade do ser humano.

A Etnomatemática tem como suas referências grupos próprios de cada cultura, identificando que é comum a toda espécie humana a satisfação de sobreviver e que tem como objetivo entender as etapas do conhecimento em diferentes ambientes investigando sobre como tais organizações foram se planejando ao longo da história de um individuo, de uma comunidade, de uma sociedade, de um povo.

A essa perspectiva D’Ambrósio (2005, p. 46), considera que a proposta pedagógica da Etnomatemática é fazer da Matemática algo vivo, lidando com situações reais no "aqui” e no “agora”. Ao fazer isso, mergulha-se nas raízes culturais e na dinâmica cultural e, reconhece-se a importância da educação das várias culturas.

Dessa forma, Knijnik (2001) tendo em vista as pesquisas voltadas para a Etnomatemática como ação pedagógica, propõe uma abordagem que, a partir da investigação das concepções, tradições e práticas matemáticas de um determinado grupo social, possui a intenção de incorporá-las ao currículo matemático como conhecimento acadêmico. Deste modo a etnomatemática é entendida como um programa que investiga as maneiras pelas quais os grupos culturais compreendem, articulam e utilizam conceitos e práticas que podem ser identificados como práticas matemáticas.

Diante disso, vemos a Etnomatemática como uma alternativa de ação pedagógica servindo como mediadora entre o conhecimento matemático adquirido por uma turma de Educação de Jovens e Adultos e o conhecimento matemático acadêmico. Isso porque cremos na possibilidade de 
uma maior identificação do estudante com o seu objeto de aprendizagem, através de motivação, conexões com aspectos afetivos, bem como a aquisição de habilidades científicas e a compreensão na importância da igualdade entre as diversas formas de manifestação de saberes matemático.

\section{Metodologia}

Este estudo trata-se de uma pesquisa qualitativa, na qual busca o significado dos dados coletados, tendo como base a percepção do fenômeno dentro do seu contexto. Conforme, Lüdke e André (1999) uma pesquisa qualitativa é aquela que se desenvolve numa situação natural, é rica em dados descritivos, tem um plano aberto e flexível e focaliza a realidade de forma complexa e contextualizada. Seu delineamento se apresenta por uma pesquisa-ação, caracterizada por um movimento dinâmico, que nos leva a um processo de transformação das práticas em práxis (FIORENTINI, LORENZATO, 2006). Desse modo o presente estudo teve como objetivo analisar o desempenho dos estudantes do EJA após uma intervenção didática sobre frações e números decimais numa perspectiva Etnomatemática.

Participaram deste estudo 15 estudantes da turma do módulo V da Educação de Jovens e Adultos (EJA) de uma escola localizada no município de Jaboatão dos Guararapes-PE. A pesquisa foi realizada em três momentos: (1) aplicação do pré-teste no primeiro encontro; (2) no segundo encontro realização de uma intervenção didática sobre frações e números racionais e (3) aplicação do pós-teste.

A atividade do pré e pós-teste continham 03 questões de fácil resolução, composto da seguinte forma: a primeira questão solicitava aos estudantes resolver as operações com frações de adição, subtração, multiplicação e divisão; a segunda questão os estudantes deveriam calcular corretamente as operações com números decimais e a terceira questão, solicitava aos estudantes que representassem as frações em numerais decimais. As questões apresentadas não tinham o caráter contextualizador, pois a proposta era que a mesma estivesse mais próxima possível das atividades realizadas em sala de aula.

A segunda etapa (ação pedagógica) foi realizada no segundo encontro a partir de uma intervenção pedagógica. Inicialmente apresentamos o tema gerador da intervenção com a seguinte frase “OS PREÇOS ESTÃO NA HORA DA MORTE”, na qual foi escrito no quadro e solicitado à opinião dos estudantes, se eles concordavam com esta afirmativa e em seguida foi realizado alguns questionamentos, tais como: O que estariam causando a alta dos preços? Como eles sabiam que os alimentos, produtos estavam com preços elevados? Onde os preços estavam mais altos nos produtos ou nos alimentos? E assim por diante. 
A partir da discussão começamos introduzir conceito de número decimal e fração fazendo uma correlação dos valores das contas de água, luz e de gás, alimentação, diversão e saúde que os estudantes descreviam a partir da realidade deles. Eles nos relataram por quanto compravam alguns alimentos no começo do ano e comparávamos o preço de janeiro com o preço do mês atual, calculando assim a diferença entre preços.

É interessante pontuar que a temática provocou várias discussões, tais como: girou em torno da política atual, enquanto alguns acreditavam que o governo estava tentando solucionar a inflação, outros tinham a opinião contrária, afirmando que o governo não estava se importando com os pobres; também nos relataram que era importante saber as operações com os números decimais para fazer as pesquisas de preços entre supermercados e para calcularem o seu troco. Ao encerrar as discussões realizamos algumas situações problemas no quadro envolvendo as quatro operações com números decimais. Após disso começamos a discussão de quanto eles gastavam com a alimentação. Eles relataram que gastavam em torno da metade do salário com a mesma, e aproveitamos essa informação e trabalhamos o conteúdo tomando como base o valor de um salário mínimo (que

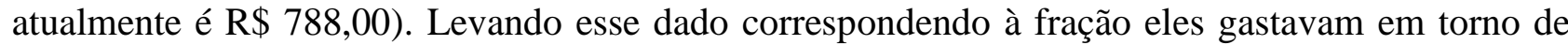
112 do salário, fomos ao quadro calcular, então perguntamos a eles e com a outra parte restante 112 do salário o que faziam? Então nos disseram que tinha que pagar contas de água, luz e de gás não sobrando nada ou pouquíssimo para a saúde e diversão. Com isso, gerou novamente a discussão girou em torno de politicas publicas, falta de médico no posto de saúde do bairro, falta de oportunidades para a diversão da família. Trazendo todos para a questão do conteúdo a ser trabalhado, usamos o quadro para resolver algumas questões utilizando as operações com números fracionários. Entretanto, muitos deles relataram que tinham esquecido as propriedades das operações com frações e nem da transformação de um número fracionário em um numero decimal o que nos levou a trabalhar tais conteúdos de forma contextualizada.

Após essa etapa convidamos os estudantes a participarem da atividade "Dominó com números decimais", onde a turma foi dividida em 05 grupos e foram dadas as seguintes instruções: (1) é um jogo de dominó só que com números decimais e fracionários; (2) a forma de jogar é semelhante do dominó tradicional e (3) o vencedor será quem conseguir jogar todas as suas peças em primeiro. Todos os estudantes tiveram interesse em participar e ficaram bastante empolgados com a atividade. De início alguns estudantes tiveram dificuldades para jogar e utilizaram um papel com rascunho para fazer os cálculos. Durante a ocorrência do jogo íamos a cada grupo certificar se estavam conseguindo jogar e tirar dúvidas. A intervenção durou em torno de 1 hora e 10 minutos.

O terceiro momento da realização desta pesquisa ocorreu após a intervenção didática, com a aplicação do pós-teste aos estudantes que se encontravam na sala de aula. Embora encontrassem 
estudantes que não estavam presentes no momento do pré-teste eles também realizaram o pós-teste. Entretanto para fins de análise serão apenas computados os pré-testes e pós-testes dos estudantes que realizaram os dois testes, nos seus respectivos momentos.

\section{Resultados e Discussão}

A abordagem Etnomatemática nesse estudo nos permitiu estabelecer conexões matemáticas em sala de aula acompanhadas de maior significado para os estudantes no ensino de frações e números decimais.

Nesse sentido, entendemos que utilizar a etnomatemática como ação pedagógica nas aulas de EJA facilita muito a compreensão e a internalização dos conceitos, significados e representações dos números fracionários e decimais.

Estudos comprovam que as operações com frações geram, sempre, muitas dificuldades nos estudantes do Ensino Fundamental, principalmente nas situações em que são exigidas algumas propriedades. Esse fato vem ratificar que somente a aplicação da regra em qualquer operação não resolve o grau de dificuldade, é fundamental que os estudantes entendam a sua construção.

Desse modo, o quadro 01 apresenta uma visão geral do desempenho dos 15 estudantes, nas questões aplicadas no pré-teste, como segue abaixo.

Quadro 01: Desempenho dos estudantes na aplicação do pré-teste. Fonte: Própria

\begin{tabular}{|c|c|c|c|c|c|c|c|c|c|c|c|c|}
\hline \multirow{2}{*}{ Result. } & \multicolumn{4}{|c|}{ Questão 01 } & \multicolumn{4}{c|}{ Questão 02 } & \multicolumn{3}{c|}{ Questão 03 } \\
\cline { 2 - 14 } & A & B & C & D & A & B & C & D & A & B & C & D \\
\hline Acertos & 01 & 01 & 13 & --- & 12 & -- & 09 & 09 & --- & --- & --- & --- \\
\hline Erros & 14 & 14 & 02 & 12 & 01 & 13 & 03 & 02 & 14 & 13 & 14 & 14 \\
\hline Branco & --- & --- & --- & 03 & 02 & 02 & 03 & 04 & 01 & 02 & 01 & 01 \\
\hline
\end{tabular}

Remetendo as análises, a questão 01 trata de resolução das operações matemáticas com frações (adição, subtração, multiplicação e divisão), observamos que os estudantes participantes da pesquisa, não souberam calcular a adição e a diferença de duas frações, com denominadores iguais. O erro que predominou foi efetuar a adição e subtração numerador com numerador e denominador com denominador, o que indica a dificuldade por não perceberem a diferença entre números fracionários e números inteiros. Segue abaixo alguns exemplos das respostas dos estudantes da questão 01: 


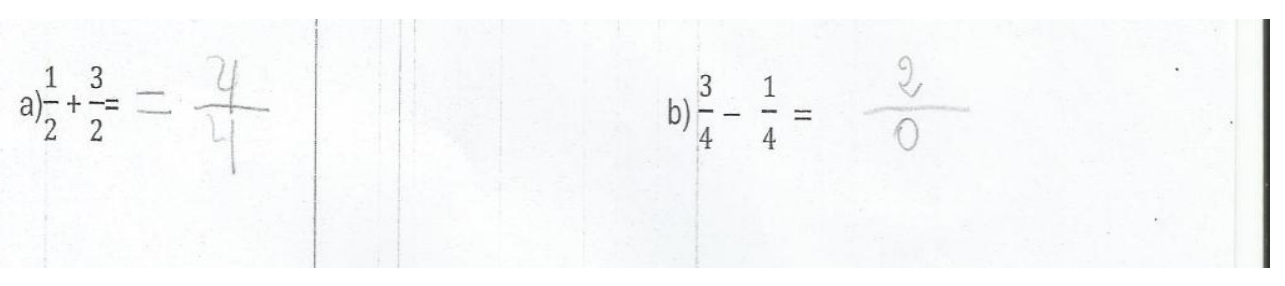

Estudante $n^{\circ} 13$

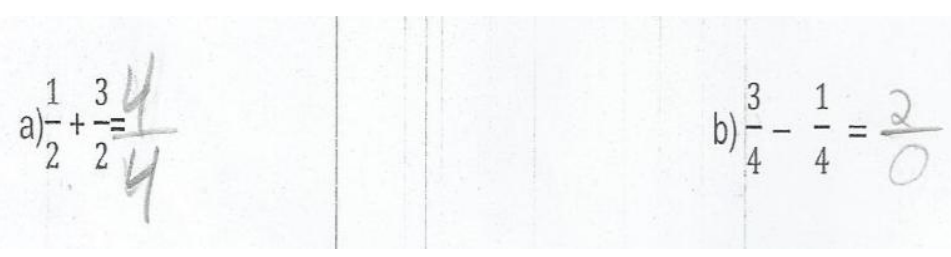

Este tipo de erro Davis e Espósito (apud CARVALHO e CARVALHO, 2001) não considera como sendo de construção de conhecimento, mas como erro no uso de conhecimentos construídos, por o aluno utilizar procedimentos inadequados mesmo tendo estruturas mentais necessárias.

Ainda na questão 01, o resultado encontrado nas operações de multiplicação de frações foi $87 \%$ de acerto pelos estudantes. Porém, na operação de divisão com fração o índice de erros foi de 100\%. O que reforça nossas inferências, de que os estudantes utilizaram o mesmo raciocínio da multiplicação dos números inteiros quando operam com os números racionais. Para ilustrar a análise, segue abaixo, exemplos de cada operação.

Estudante $n^{\circ} 02$

c) $\frac{3}{5} \cdot \frac{4}{2} \frac{12}{70}$

d) $\frac{6}{1}: \frac{8}{2}=$

Estudante $\mathrm{n}^{\circ} 05$
c) $\frac{3}{5} \cdot \frac{4}{2}=\frac{12}{10}$
d) $\frac{6}{1}: \frac{8}{2}=\frac{8}{3}$

Estudante $\mathrm{n}^{\mathrm{o}} 06$

$$
\text { c) } \frac{3}{5} \cdot \frac{4}{2}=
$$$$
\text { d) } \frac{68}{12}=
$$ 
De acordo com o resultado observa-se que os estudantes além de não saberem fazer divisão de números inteiros não tem a compreensão da divisão de números fracionários, daí o alto índice de erros nesta alternativa. Percebemos que essa dificuldade não advém apenas da pouca compreensão de números fracionários, mas também a falta de domínio das regras operatórias evidenciando assim, obstáculos encontrados por eles na divisão de frações.

A questão 02 apresenta quatro alternativas de operações simples (adição, subtração, multiplicação e divisão) com números decimais. Dentre as operações a que tratava de uma subtração, foi à única que não ocorreu acerto. As demais operações o percentual de acerto girou em torno de $80 \%$ para a operação com adição e $60 \%$ com multiplicação e divisão. Percebemos, então, que os alunos não apresentaram dificuldade de posicionar a vírgula, desse modo podemos considerar que, embora, os estudantes tenham a compreensão da operação com números decimais, à maioria dos erros cometidos está relacionados com as operações desejadas. Segue, alguns exemplos ilustrativos, abaixo:

Estudante $n^{\circ} 03$

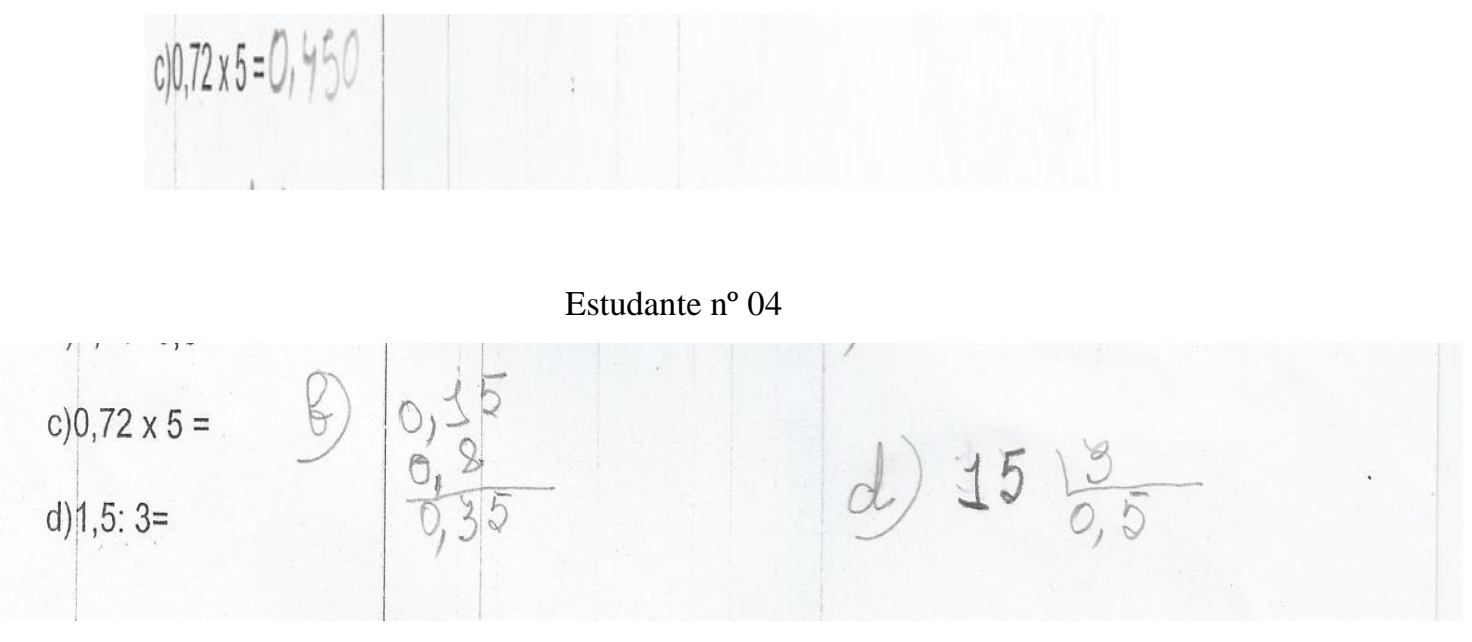

A questão três solicitou aos estudantes representar as frações $\frac{1}{2} ; \frac{3}{4} ; \frac{5}{10} ; \frac{5}{10}$ em números decimais. Como esta questão tem o mesmo principio de resolução transformar números fracionários em números decimais, a primeira dificuldade encontrada pelos alunos foi saber qual o método de resolução a ser empregado; a segunda dificuldade está na resolução que deve ser uma divisão, sendo esta a operação em que os alunos apresentam o maior grau de dificuldade, nessa questão não houve nenhum acerto.

Ao finalizarmos a análise dos resultados do pré-teste, percebe-se que o modo como o conteúdo foi trabalhado em sala de aula parece ter sido insuficiente para dar sentido às operações de 
frações na aprendizagem dos estudantes do EJA. Desta forma, a proposta de intervenção didática, teve como objetivo trabalhar os conteúdos de fração e números decimais na perspectiva pedagógica da Etnomatemática de forma contribuir para a construção do conhecimento dos estudantes sobre fração e números decimais.

Neste momento iremos realizar a segunda etapa da análise dos dados a partir dos resultados encontrados no pós-teste realizado após a intervenção pedagógica. De um modo geral os resultados apresentados no pós-teste foram bastante significativos quando comparados com o pré-teste. Segue o quadro geral dos resultados do desempenho dos 15 estudantes após a intervenção pedagógica.

Quadro 02: Resultados do desempenho dos estudantes no pós-teste. Fonte: Própria.

\begin{tabular}{|c|c|c|c|c|c|c|c|c|c|c|c|c|c|}
\hline \multirow{2}{*}{ Result. } & \multicolumn{4}{|c|}{ Questão 01 } & \multicolumn{4}{c|}{ Questão 02 } & \multicolumn{4}{c|}{ Questão 03 } \\
\cline { 2 - 14 } & A & B & C & D & A & B & C & D & A & B & C & D \\
\hline Acertos & 13 & 11 & 13 & 08 & 12 & --- & 08 & 13 & 13 & 11 & 14 & 14 \\
\hline Erros & 02 & 03 & 02 & 04 & 02 & 13 & 05 & 01 & 01 & 03 & 01 & 01 \\
\hline Branco & -- & 01 & -- & 03 & 01 & 02 & 02 & 01 & 01 & 01 & --- & -- \\
\hline
\end{tabular}

Conforme os resultados apresentados no quadro acima, observamos de um modo geral que os estudantes conseguiram superar alguns obstáculos na resolução das atividades aplicadas. Os resultados revelam que exceto a operação do item "B" da questão $02(0,15-0,8=)$, as demais questões os estudantes tiveram um desempenho em média $78 \%$. Na realidade a operação da questão 02 demonstra uma dificuldade específica dos estudantes em resolver a subtração com números decimais por ser decorrente da dificuldade de resolver subtração de números inteiros.

A terceira etapa da análise consiste um estudo comparativo com os resultados encontrados no pré-teste com o do pós-teste. Essa análise comparativa permitiu verificar que foi no pós-teste que se observam melhores resultados, principalmente nas operações da questão 03 que trata das representar frações em números decimais, onde o quantitativo de acertos foi na ordem de $73 \%$ em relação ao pré-teste. Vale salientar, que em relação ao pré-teste os itens que obteve uma percentagem de respostas corretas mais baixas, estão mais direcionados para as dificuldades de resolução de operação matemáticas simples com números inteiros.

Após a intervenção pedagógica não se verificaram grandes diferenças entre as operações, pois a maioria alcança em torno de $73 \%$ de acertos. Desse modo, podemos também verificar que, mesmo após a intervenção, continua a haver dificuldade por parte de alguns estudantes em resolver os itens relacionados à divisão de fração como também subtração com números decimais. 


\section{Conclusões}

Aprender na fase adulta exige bastante esforço tanto da parte do estudante para compreender o conteúdo a ser trabalhado, como por parte do professor que precisa utilizar uma metodologia adequada. A complexidade dos cálculos que envolvem as operações com frações, operações com números decimais e a transformação de números fracionários em decimais, trazem, muitas vezes, aos estudantes dificuldades e requer certas habilidades para poderem estruturar e resolverem as operações.

É a partir dessas implicações na aprendizagem de frações e números decimais que concordamos com Monteiro (2004, p.445) quando afirma que a Etnomatemática nos permite pensar no conhecimento como algo impregnado de valores culturais e sociais não fragmentados, constituindo-se de elementos mais amplos que os conteúdos específicos.

A abordagem Etnomatemática nesse estudo nos permitiu estabelecer conexões matemáticas em sala de aula acompanhadas de maior significado para os alunos no ensino de frações e números decimais.

Nesse sentido, entendemos que utilizar a etnomatemática como ação pedagógica nas aulas de EJA facilita muito a compreensão e a internalização dos conceitos, significados e representações dos números fracionários e decimais.

A pesquisa atingiu seu objetivo na proporção em que possibilitou a contextualização do cotidiano dos alunos com o ensino da Matemática, numa abordagem Etnomatemática revelando uma excelente ferramenta a ser utilizada por professores na Educação de Jovens e Adultos.

\section{Referências}

BRASIL. MEC. Parâmetros Curriculares Nacionais (5ª a 8ª séries). Brasília: MEC/SEF, 1997.

CARVAlHO, D. D. M.; CARVALHO M. M. Para compreender o erro no processo ensinoaprendizagem. Presença Pedagógica. v. 7, n. 42, p. 61-75, 2001.

D’AMBRÓSIO, U. Etnomatemática: elo entre as tradições e a modernidade. Minas Gerais: Editora Autêntica, 2001.

D’AMBRÓSIO, U. As matemáticas e seu entorno sociocultural. Memorias del Primer Congreso Iberoamericano de Educación Matemática, Paris, 1991.

D’AMBRÓSIO, U. Sociedade, cultura, matemática e seu ensino. Revista Educação e Pesquisa. São Paulo, v. 31, p. 99-120, 2005. 
FERNANDES, S. S. A contextualização no ensino de matemática - um estudo com alunos e professores do ensino fundamental da rede particular de ensino do Distrito Federal. \{online\} Disponível na internet via: https://www.ucb.br/sites/100/103/TCC/.../SusanadaSilvaFernandes.pdf. Capturado em 10 de Junho de 2015.

FIORENTINI, D.; LORENZATO, S. Investigação em educação matemática: percurso teóricometodológico. Campinas, SP: Autores Associados, 2006. Coleção Formação de Professores.

KNIJNIK, G. Educação Matemática, exclusão social e política do conhecimento. Bolema. Rio Claro, UNESP, Ano 14, n. 16, p.- 12-28, Out. 2001.

LUDKE, M. e ANDRÉ, M. E. D. A. Pesquisa em educação: abordagens qualitativas. São Paulo: EPU, 1999.

MONTEIRO, A. Parte 3- Etnomatemática e Formação de Professores. In: KNIJNIK, G.; WANDERER, F.; OLIVEIRA, C.J. (orgs). Etnomatemática, Currículo e Formação de Professores: A Etnomatemática em cenários de escolarização: alguns elementos de reflexão. Santa Cruz do Sul, 2004 p. 432-446.

MORAES, Lidiane Aparecida Breguedo. Etnomatemática como pratica de ensino. \{online\}. Disponível na internet via: www.uems.br/semana/2010/artigos/04.pdf arquivo capturado em 22 de Maio de 2015. 